\title{
Response to: Comment on: "Sex-Specific Differences \\ in Running Injuries: A Systematic Review with Meta-Analysis and Meta-Regression"
}

\author{
Karsten Hollander ${ }^{1}$. Jan Wilke ${ }^{2} \cdot$ Astrid Zech $^{3}$
}

Accepted: 14 August 2021 / Published online: 4 September 2021

(c) The Author(s) 2021

\section{Dear Editor,}

We really appreciate the Letter to the Editor by Nnamani Silva et al. [1], which added valuable information and discussion to our systematic review titled "Sex-specific differences in running injuries: a systematic review with metaanalysis and meta-regression" [2].

The unequal sample size of sexes, with more male runners in road racing events and more female novice runners, emphasizes the need to take a closer look at moderating factors. Generally, detailed reporting of potential effect modifiers is highly encouraged in primary studies to increase the often limited power of meta-regressions. Regardless, in our meta-analysis, the exclusive inclusion of studies with both sexes for the same running background (level) and use of incidences for risk ratio calculation of each study should have reduced the influence of unequal sample size distribution. However, we agree that the combination of studies with different running levels in the same pooled risk ratio calculation may have led to a greater weighting of one running level (towards the level with the higher number of studies). In our meta-regression, we quantified the running level with the competition distance, training duration, and training mileage but cannot completely rule out that a differentiation for the

An author's reply to this comment is available at https://doi.org/10. 1007/s40279-020-01412-7.

Karsten Hollander

karsten.hollander@medicalschool-hamburg.de

1 Institute of Interdisciplinary Exercise Science and Sports Medicine, MSH Medical School Hamburg, Am Kaiserkai 1, 20457 Hamburg, Germany

2 Institute of Occupational, Social and Environmental Medicine, Goethe University Frankfurt, Frankfurt, Germany

3 Department of Human Movement Science and Exercise Physiology, Institute of Sport Science, Friedrich Schiller University Jena, Jena, Germany competition level (road racing vs. novice) would have led to different results.

In conclusion, the points raised by Nnamani Silva et al. [1] highlighted another important aspect in the relevant consideration of sex as a variable for equal sampling in addition to the possible impact of sex specificity in the etiology and probably prevention and rehabilitation of running-related injuries.

\section{Declarations}

Funding Open Access funding enabled and organized by Projekt DEAL.

Conflict of interest Karsten Hollander, Jan Wilke, and Astrid Zech have no conflicts of interest relevant to the content of this letter.

Open Access This article is licensed under a Creative Commons Attribution 4.0 International License, which permits use, sharing, adaptation, distribution and reproduction in any medium or format, as long as you give appropriate credit to the original author(s) and the source, provide a link to the Creative Commons licence, and indicate if changes were made. The images or other third party material in this article are included in the article's Creative Commons licence, unless indicated otherwise in a credit line to the material. If material is not included in the article's Creative Commons licence and your intended use is not permitted by statutory regulation or exceeds the permitted use, you will need to obtain permission directly from the copyright holder. To view a copy of this licence, visit http://creativecommons.org/licenses/by/4.0/.

\section{References}

1. Nnamani Silva ON, Armijo PR, Feld LD, Mascarenhas Monteiro JS, Pham R, Tenforde AS. Comment on: "Sex-specific differences in running injuries: a systematic review with meta-analysis and meta-regression." Sports Med. 2021. https://doi.org/10.1007/ s40279-021-01548-0.

2. Hollander K, Rahlf AL, Wilke J, Edler C, Steib S, Junge A, Zech A. Sex-specific differences in running injuries: a systematic review with meta-analysis and meta-regression. Sports Med. 2021;51:1011-39. https://doi.org/10.1007/s40279-020-01412-7. 